\title{
Outlets: The New Favorite of Apparel Industry
}

\author{
Yanhua Sun \\ College of Art and Appareluages, Tianjin Polytechnic University, Tianjin 300384, China \\ E-mail: sunyanhua232@126.com
}

\begin{abstract}
In recent years, along with the fast development of China retail industry, outlets, the brand-new retailing form has entered China. This paper briefly analyzes the advantages and disadvantages of outlets, and puts forward three tactics for its operation.
\end{abstract}

Keywords: Brand, Outlets, Apparel retailing

Along with the improvement of people's living level, consumers pursue for brands more and more. Domestic people's needs for apparel are changed from basic clothes toward brands. Confronting with this need, domestic market has to consider what it can provide with for consumers due to its limited brands. It is also a project in front of apparel production companies. Outlets, the unique sale channel, become a win-win choice for both apparel companies and consumers. Specialists predict that outlets will become the most powerful retailing form in future apparel industry.

In recent ten years, many world-famous brands enter China market. Data show that $70 \%$ of well-known consumption brands have already entered China market. Among these brands, most have already been accepted by domestic consumers. For consumers who just step into the brand consumption field, the prices of goods in brand shops are too high, and the goods in small shops are hard to value. Besides, they have not sufficient time to hope for discount in brand shops. The emergence of outlets just meets the needs of these kinds of consumers. Therefore, outlets have kind of competitive advantages indeed. What the temptation is as we can choose favorite clothes among first-class apparel brands that have lower prices. Outlets, as a completely-imported mode, are a final retailing form after chain stores, convenient stores, promotion stores, and other new commercial modes.

\section{Origin of outlets}

Outlets is kind of shopping mall that chiefly sales past-season, and off-shelf brand apparels, which can provide with entertainment and discounted brand goods at the same time. The typical outlets are composed of apparel outlets, large-scale discount goods, entertainment, and restaurant. Outlets are originated from producers of brand apparels, and brand direct-sale centers that mainly sale bad stock goods at very lower prices in late 19th century. Till 70s in last century, brand direct-sale centers gradually evolved into the outlets that combine apparel producers, brand owners, restaurants, large-scale discounted-goods malls, and entertainment facility providers.

America is the cradle of outlets. It is also the most developed region for operating outlets (Decai Tang, 2005). During the 80s to 90s in last century, outlets have gained most rapid development in America. Although in recent twenty years the development becomes slower, American outlets businesses accomplished integration. Most outlets are mastered by several commercial businesses. From the form of outlets, there is both shopping mall and outlets village. But sale field is seldom.

Perhaps many Chinese consumers may regard discount stores as small business. But as a matter of fact, discount stores, as a new commercial mode, have shared the retailing market together with merchandise malls, supermarkets, and large specialized stores, in European and American countries. Especially under the situation of slumping economy and rising unemployment ratio, discount stores possess unique advantages of low-cost operation, and high circulation. In recent American commercial companies' list, three of the first five members are discount stores. Half of Wal-Mart's annual sales are coming from its discount stores.

In foreign countries, the discount stores refer to producers' direct-sale shops. It has three preconditions. Firstly, the discount stores must have first-class brands. Secondly, although the discount stores sale past-season, and off-shelf goods, they must have sufficient brands sources and can renew goods. Thirdly, goods in discount stores are cheap. Today, many consumers pursue not only brands but also high quality and lower price. Outlets can bring about "great brands, lower prices" for consumers.

Today, discount stores have already become such a retailing form that chiefly sale self-owned brands and fast-circulated goods, with restricted goods types, limited business areas, services, and lower operation costs, providing with worthy goods for consumers. 


\section{Advantages of outlets}

\subsection{Price advantage}

New product' retail price $=$ material costs + labor costs + management costs + capital costs + profits + marketing costs + brand advertising costs + logistics costs (Zhengxiu Lin, 2004).

Special product' price $=$ material costs + labor costs + production costs

Most consumers are longing for possessing world famous brands. However, higher prices make common consumers stop at eye shopping. Apparently, outlets can meet consumers' needs for well- known brands to certain degree. The pursuit of brand consumers for brand goods includes two stages, namely the longing-for stage of brand consumption, and the stage of brand fashion consumption. Most brand fashion consumers prefer to purchase brand goods in brand stores or high-class shopping mall. But the longing-for brand consumers hope to buy brand goods at lower prices. Outlets provide with more consumption chances for the later.

As far as apparels are concerned, the values exist in the fashion. Each brand has its depreciation rate. For a famous brand, the right-season apparel is at $100 \%$ price, next year $50 \%$, the year after next $30 \%$. One of reasons for cheapness is past-season. Entering outlets, consumers should understand this essential concept.

Diversified consumption ideas make consumers accept discount stores completely. Everyone has his own consumption idea. No matter what it is pursuing new goods and commonness, or uniqueness and cheapness, the choice is based on self preference. People who enter outlets emphasize brands and lower prices. Commercial businesses should follow consumers' consumption needs.

\subsection{A flexible way of solving the stock issue}

As well-known brands solve their stock issues, outlets contribute a lot. According to world famous brands' practices, public discount or special promotion has become a must. Specialists think that it is universal to change past-season and off-shelf products from fashion consumption into common consumption. Outlets can not only help to solve the stock issue effectively, but also separate normal-price goods from special-price goods. It is a popular way for world famous apparel brands.

However, many domestic companies do not emphasize discount stores. They even refuse to make discount forever. In their opinions, discount may hurt the image of brand. But if we take outlets as a part of brand operation, establishing brand for outlets, imposing strict requirements for market, customers, and finals, separating normal-price products from special-price products as much as possible, outlets, as a way of solving the stock issue, will bring about maximized benefits for consumers and companies.

Regard outlets as kind of brands' further development toward their potential consumers and a complement for low and medium consumption market. On one hand, it can expedite the circulation of normal-price goods. On the other hand, it can expand brands' inferior market, controlling brands' stock rationally, and ensuring brands' healthy growth. Along with the complete openness of domestic retailing industry, amount of foreign brands enter China market. Domestic brand operation companies can introduce mature foreign outlets companies or co-operate with them, making best use of their effective management, and their sufficient goods sources to cultivate domestic market.

\subsection{Non-discount service}

Although outlets sale past-season and off-shelf goods, they still stand for brands. Therefore, excellent services are always powerful weapons to attract consumers. Bright smile, kindness, active attitudes, and together with discount can help to complete purchases. Services in outlets should not be discounted.

\subsection{Benefit the regulation of market}

As discount has become a popular and regular way for commerce gradually, it will weaken the strengths of commercial companies, and it may disturb the brands' price system, which may make consumers lose confidence on brands. Emergence of outlets can effectively control this irrational discount. Normal-price goods and special-price goods have different sale channels. Market separates normal-price goods from special-price goods completely, which helps consumers form exact position and understand clearly what prices are.

\section{The development and problems of outlets in domestic market}

As the first outlets come into being in Beijing, some people predict that this new retailing form will develop into a huge industry rapidly in recent years. In the Classification of Retailing issued by Ministry of Commerce, outlets, together with TV purchase, online stores, are named as new retailing modes. Indeed, outlets, in other words, companies' direct-sale centers, have already developed for more than one hundred years (Xu Liu, 2003). Presently, there are 275 large outlets centers in America. In contrast, till late 2002, it is a blank in China. Since Beijing Yansha 
Youyi Shopping City set up the first outlets shopping center in Dec. 2002, the outlets concept has begun to spread over China. As a result, different outlets are founded all over the country.

However, present discount stores appeared in China are not real outlets. Problems include these aspects as follow.

\subsection{Scarcity of goods sources and too much counterfeits}

Domestic outlets do not have reliable goods sources. Limited goods can not satisfy the large-scale operation. Many commercial stores are incapable of obtaining "producers' direct-sale" sources. The stability is poor. It is common for certain brand that appears in outlets one month but disappears next month. If outlets prefer to prosperity, it must depend on first-class brands to attract more consumers. However, most outlets do not construct direct connection with well-known brands. Especially, some first-class brands do not enter or merely wait for entering China's retailing market. Since normal-price goods do not enter the market, how do discount goods obtain business opportunities? Present outlets are more like special-sale market. In today's outlets, it is hard to find real first-class brands but few out-of-date brands or high-price goods. In stead, these outlets are filled with numerous unknown brands. Although some products are marked with "world brands", they are produced in domestic market by China's business man who has registered his companies in foreign countries. By outlets, commercial companies sale some "world brands" that are unknown in China.

\subsection{Confusion of price system}

Products sold in outlets merely have discount prices. Consumers do not know the original prices of products except learning from salesman's oral promise. As a rising retailing form, the price system should be further perfected, which can ensure that consumers know prices of products clearly.

\section{Three tactics should be mentioned in operating outlets}

\subsection{Tactic of brand ------ build up consumers' confidence}

Because outlets are a brand-new retailing form in China, some consumers may visit it out of curiosity. In this stage, commercial stores should focus on the construction of credit. Sometimes, they have to sacrifice their short-term profits. But in the long run, it can benefit not only the commercial stores but also the industrial development. As far as products are concerned, because most of them are past- season or imperfect more or less, it is necessary for salesman to make discount reasons clear, and help consumers make purchases faithfully. In the price aspect, pay more attention on psychological strategy. In other words, value the products from the angle of consumers.

\subsection{Tactic of orientation ------ uniqueness}

In a sense, the orientation of outlets in retailing industry is determined by its positioning tactic. If the orientation of outlets is similar to that of supermarket and shopping mall, they may step in to a trap. That is an inherent shortcoming of outlets. Outlets must focus on consumers who are at low and medium level in pursuing brands instead of people who pursue fashion consumption. Outlets should set up the orientation from every aspect.

\subsection{Tactic of superiority ----- advantage of costs}

Outlets follow a low-cost way, advertising for "buying brands, not waiting for promotion". In specific, it is to shorten stock channels, and decrease costs of chain business. Firstly, outlets should decrease costs as much as possible, imposing strict and scientific management on products' types, goods' purchases, stock, location of outlets, products' arrangement in outlets, and sale stages. Secondly, outlets can enlarge the scale and decrease costs by chain business. The chain business should be accomplished really but not merely in form. Besides, outlets should make best use of China's self-possessed brands.

Along with the gradual development of China's retailing market, consumers' rational consciousness of consumption is improving step by step. More and more people accept the pure brands. In a sense, outlets, the new retailing form, are facing an excellent commercial opportunity. Presently, the primary factor is the self-restriction of operators and the improvement of management, which can guarantee the quality of products. By this way, the operation of outlets can grow into maturity in a real sense. Since the outlets in America become the paradise of consumers, and there are successful TK MAX outlets in London, we can hold the belief that China will have its own world famous outlets in future.

\section{References}

Lin, Zhengxiu. (2004). Winning Success in Retail Industry. Guangzhou: Nanfang Daily Press.

Liu, Xu. (2003). Past, Today, and Future of Modern Commodities Retail in America. Beijing: Tsinghua University Press.

Tang, Decai. (2005). Modern Marketing Course. Beijing: Tsinghua University Press. 